\title{
Hydroxamate Titanium-Organic Frameworks and the Effect of Siderophore-Type Linkers over Their Photocatalytic Activity
}

\author{
Natalia M. Padial, ${ }^{\dagger, \perp, \ddagger(0)}$ Javier Castells-Gil, ${ }^{\dagger,}{ }^{\ddagger}$ Neyvis Almora-Barrios, ${ }^{\dagger}$ María Romero-Angel,
} Iván da Silva, ${ }^{\S}$ Mariam Barawi, ${ }^{\| \odot ~ A l b a ~ G a r c i ́ a-S a ́ n c h e z, ~ " V i ́ c t o r ~ A . ~ d e ~ l a ~ P e n ̃ a ~ O ’ S h e a, ~}{ }^{\| \odot}$ and Carlos Martí-Gastaldo $*^{*} \dagger$

${ }^{\dagger}$ Universidad de Valencia (ICMol), Catedrático José Beltrán-2, 46980 Paterna, Spain

${ }^{\S}$ ISIS Facility, Rutherford Appleton Laboratory, Chilton, Didcot, Oxfordshire, OX11 0QX, United Kingdom

"IMDEA Energy Institute, Parque Tecnológico de Móstoles, Avenida Ramón de la Sagra, 3, 28935 Móstoles, Madrid, Spain

\section{Supporting Information}

ABSTRACT: The chemistry of metal-organic frameworks (MOFs) relies on the controlled linking of organic molecules and inorganic secondary building units to assemble an unlimited number of reticular frameworks. However, the design of porous solids with chemical stability still remains limited to carboxylate or azolate groups. There is a timely opportunity to develop new synthetic platforms that make use of unexplored metal binding groups to produce metal-linker joints with hydrolytic stability. Living organisms use siderophores (iron carriers in Greek) to effectively assimilate iron in soluble form. These compounds make use of hard oxo
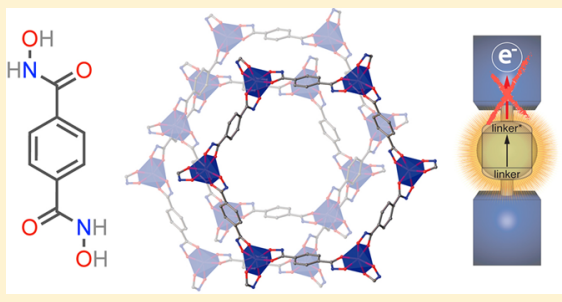
donors as hydroxamate or catecholate groups to coordinate metal Lewis acids such as iron, aluminum, or titanium to form metal complexes very stable in water. Inspired by the chemistry of these microorganisms, we report the first hydroxamate MOF prepared by direct synthesis. MUV-11 (MUV = materials of Universidad de Valencia) is a crystalline, porous material (close to $800 \mathrm{~m}^{2} \cdot \mathrm{g}^{-1}$ ) that combines photoactivity with good chemical stability in acid conditions. By using a high-throughput approach, we also demonstrate that this new chemistry is compatible with the formation of singlecrystalline phases for multiple titanium salts, thus expanding the scope of accessible precursors. Titanium frameworks are regarded as promising materials for photocatalytic applications. Our photoelectrochemical and catalytic tests suggest important differences for MUV-11. Compared to other Ti-MOFs, changes in the photoelectrochemical and photocatalytic activity have been rationalized with computational modeling, revealing how the chemistry of siderophores can introduce changes to the electronic structure of the frontier orbitals, relevant to the photocatalytic activity of these solids.

\section{INTRODUCTION}

Metal-organic frameworks (MOFs) are crystalline porous materials built from the interlinking of metal nodes and organic linkers. Their unparalleled chemical and structural flexibility provides a rich landscape of pore environments and physical properties of interest in gas storage/separation, catalysis, sensing, or proton transport to cite a few. ${ }^{1}$ MOFs based on divalent transition metal ions have led to numerous open architectures with increasingly high porosity. However, they often suffer from poor chemical stability, in particular to water, thus limiting their application. This problem can be circumvented by introducing strong metal-linker coordination bonds less prone to hydrolysis by reaction of soft azolate linkers with soft divalent metals, i.e., ZIF and pyrazolate families ${ }^{2,3}$ or the mesoporous PCN-602. ${ }^{4}$ Another possibility relies on the combination of hard carboxylates with highly charged metals $\left(\mathrm{M}^{3+}\right.$ and $\left.\mathrm{M}^{4+}\right)$. This last approach was first exemplified for $\mathrm{Al}^{3+}, \mathrm{Fe}^{3+}$, and $\mathrm{Cr}^{3+}$ in the MIL-53, ${ }^{5} \mathrm{MIL}-100,{ }^{6}$ and MIL-101 ${ }^{7}$ families, followed by the discovery of the UiO-66 MOFs based on $\mathrm{Zr}_{6} \mathrm{O}_{4}(\mathrm{OH})_{4}\left(\mathrm{RCO}_{2}\right)_{12}$ clusters as SBUs in $2008 .^{8}$ This accelerated the discovery of a high number of materials based on isostructural $\mathrm{Zr}^{4+}$ or $\mathrm{Hf}^{4+}$ metal-oxo clusters, ${ }^{9,10}$ for a substantial increase in the number of stable MOFs reported in the last years. ${ }^{11,12}$

Compared to these metals, titanium is relatively low-cost, less toxic, and redox active and displays photocatalytic properties. Notwithstanding these advantageous features, the synthesis of $\mathrm{Ti}^{4+}$ crystalline open frameworks still remains very challenging likely due to the high reactivity of the titanium sources employed. Common precursors are prone to hydrolysis in the solvothermal conditions used in MOF synthesis, which often leads to uncontrolled precipitation of amorphous oxides or hydroxides. ${ }^{13}$ As a result, only a few porous Ti-MOFs have been prepared by direct reaction with polycarboxylate linkers. ${ }^{14-23}$ Unfortunately, we are still far from being capable of rationalizing the design of new topologies arguably due to the arbitrary polycondensation reactions of $\mathrm{Ti}$ cations in solution, which limit our control over the nuclearity of the metal-oxo clusters that will be incorporated into the framework. An interesting perspective in this context is the use of alternative linkers that allow for certain control over this

Received: May 7, 2019

Published: July 18, 2019 
equilibrium, based on strong complexation of the metal to direct the formation of foreseeable framework nodes. This is the case of Ti-CAT-5, ${ }^{24}$ NTU-9, ${ }^{25}$ and MIL-167, ${ }^{26}$ in which the replacement of carboxylates with chelating catecholate or phenolate groups favors the formation of mononuclear $\mathrm{Ti}$ nodes with octahedral coordination. Still, porosity in these solids can be severely limited by structural interpenetration or the presence of cations for charge neutrality.

These precedents encouraged us to investigate the use of siderophore-type linkers by replacing carboxylate with hydroxamic units (-CONHOH) into already known MOFforming polycarboxylate linkers (Scheme 1). Compared to

Scheme 1. Structure of Benzene-1,4-dihydroxamic Acid ( $\mathrm{H}_{4}$ bdha)

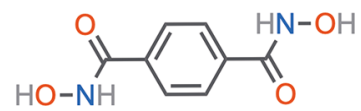

carboxylates, hydroxamates are well known for their medical applications and ability to form strong metal-linker joints. ${ }^{27}$ Still, there is no precedent for their use as connectors to form porous, crystalline materials by direct synthesis. This is arguably due to the difficulties in controlling the formation of strong metal-hydroxamate coordination bonds under reversible conditions to avoid the formation of amorphous materials with intrinsic disorder. To date, hydroxamic acid linkers have been incorporated only postsynthetically into $\mathrm{Zr}(\mathrm{IV})-\mathrm{UiO}-66$ frameworks via solvent-assisted linker exchange reactions to produce daughter materials with enhanced stability. ${ }^{28}$ This work highlights the difficulties in using hydroxamic linkers to produce reticular solids by direct synthesis. Herein, we report the first hydroxamate-based MOF prepared by de novo synthesis. MUV-11 (MUV = materials of Universidad de Valencia) is a crystalline, porous material that combines photoactivity with a surface area close to $800 \mathrm{~m}^{2} \cdot \mathrm{g}^{-1}$. Compared to titanium frameworks based on other binding groups, the use of a siderophore binder results in outstanding chemical stability in acid conditions and introduces drastic changes to the frontier crystalline orbitals that control charge transfer kinetics and thereby the photocatalytic activity of this material.

\section{RESULTS AND DISCUSSION}

Synthesis and Structure of MUV-11. Benzene-1,4dihydroxamic acid $\left(\mathrm{H}_{4}\right.$ bdha $)$ can be prepared by one-step reaction of the ester derivative of terephthalic acid with a methanolic solution of hydroxylamine under basic conditions. ${ }^{29}$ This reaction is well fitted for multigram-scale linker synthesis as it proceeds with yields close to 65\% (see Experimental Section for synthetic details; S1, S2, and S3). MUV-11 was first prepared by solvothermal reaction of $\mathrm{H}_{4}$ bdha with titanium(IV) isopropoxide in dry $\mathrm{N}, \mathrm{N}$-dimethylformamide (DMF) at $120{ }^{\circ} \mathrm{C}$ by using acetic acid as modulator. The product can be formed in capped vials or Teflon liners or easily adapted to high-scale synthesis by using glass bottles up to 20 -fold. Reagent manipulation was carried out in the glovebox to avoid partial hydrolysis of the titanium precursor.

The solid was isolated as orange crystals with hexagonal morphology and sizes ranging from 10 to $20 \mu \mathrm{m}$ (Figures $1 \mathrm{~b}$ and S3). Their small size and intertwined nature prevented

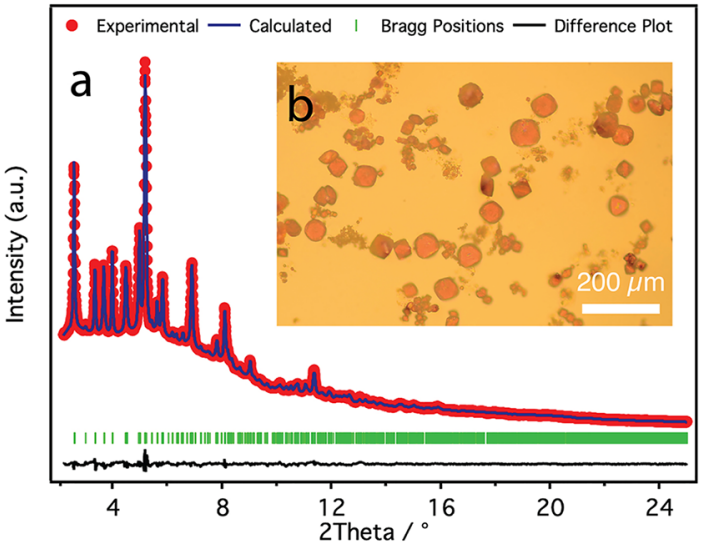

Figure 1. (a) Rietveld refinement of MUV-11 crystals $(\lambda=$ $0.413070(1)$ A). (b) Size and morphology of the crystals formed.

structural determination with an in-house diffractometer. Synchrotron radiation (ALBA, BL13-XALOC) was limited by very weak diffraction at high-angle resolution and allowed us to determine only the space group and cell parameters. Electron density maps were used to determine the position of $\mathrm{Ti}$ atoms, organic linkers, and the overall network connectivity. This preliminary structural model was then modified with the Materials Studio (MS) 2017 R2 and optimized with density functional theory (DFT) methods (Section S4) to produce a starting model for the refinement of the high-resolution powder X-ray diffraction data (PXRD) also collected at the synchrotron (ALBA, BL04-MSPD). As shown in Figure 1a, Rietveld refinement converged with excellent residual values $\left(R_{\text {wp }}=1.47 \%, R_{\text {exp }}=1.15 \%\right)$ for a trigonal $P 3_{2}$ space group with cell parameters $a=18.1230(8) \AA$ and $c=11.2238(7) \AA$. Comparison of the atomic coordinates generated by DFT and Rietveld refinement is summarized in Tables S5 and S6. MUV11 is based on octahedrally coordinated, single-node $\mathrm{Ti}(\mathrm{IV})$ atoms. They are coordinated to six oxygen atoms from the hydroxamic groups of three $\mathrm{H}_{n}$ bdha $(n=1,2)$ units that interconnect two neighboring metal nodes. This results in a honeycomb-like lattice in which simple-node metal atoms and organic linker act as vertices and edges of the hexagonal tiling for a 2,3-c 2-nodal net topology (Figures 2a and S16). This is reminiscent of the in-plane structure of NTU-9, ${ }^{25}$ built from 2,5-dihydroxiterepthalate $\left(\mathrm{H}_{2} \mathrm{dhtp}\right)$ linkers, with 1.5 times bigger pore widows as a result of the elongation of the linker in MUV-11 (Figure S15). The hydroxamic group is capable of adapting the coordination mode of dhtp connectors into a fivemembered chelate, but it introduces differences that result in important changes to the internal structure of the layers. As summarized in Figure S17, the - $\mathrm{OH}$ groups in dhtp form part of the central aromatic ring, restricting the linker to adopt a planar conformation upon metal coordination with a twist angle between neighboring rings of $4.4^{\circ}$ in NTU-9. In turn, the hydroxamate group lies off the ring and can rotate more freely to adopt the conformation that is more favorable energetically. As a result, the planes of the aromatic ring and one of the TiOCNO chelates deviate $16.3^{\circ}$ from planarity to produce a highly distorted octahedron. This is likely the reason for the layers in MUV-11 adopting a zigzag configuration (Figure 2b) compared to their planar structure in NTU-9. The internal rotation of the hydroxamate units is also influenced by the formation of $\mathrm{NH} \cdots \mathrm{O} \mathrm{H}$-bonds between neighboring layers of 2.74(14) and 2.73(11) $\AA$ (Figure S18 and Table S7). We 


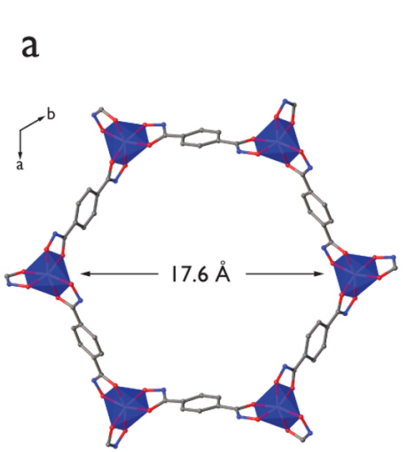

b

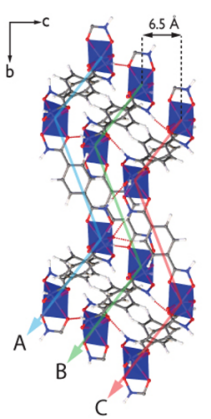

C
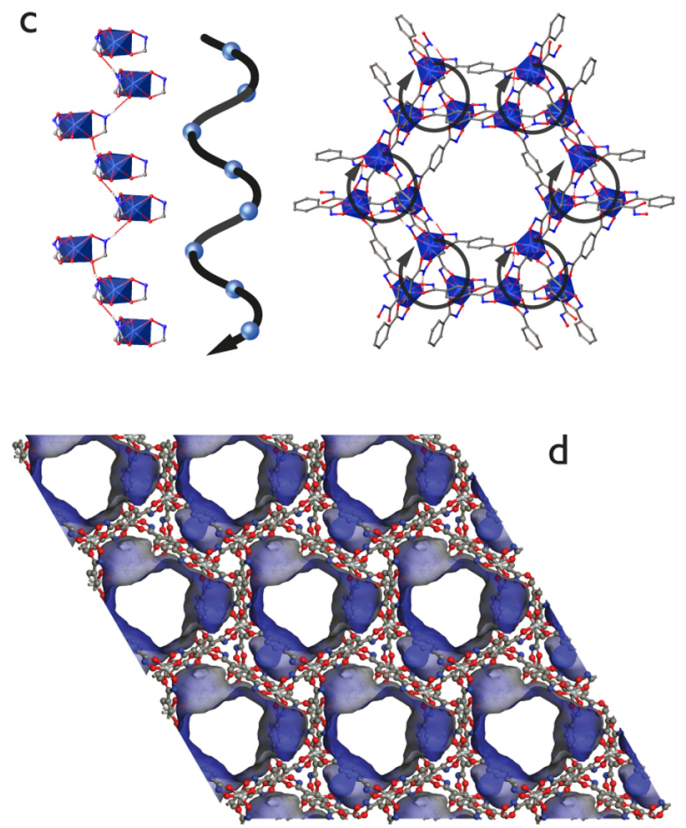

Figure 2. (a) Honeycomb lattice in MUV-11 showing the internal dimensions of the pore window in the layer. (b) $\cdots$ ABC $\cdots$ packing of the corrugated layers of $\left[\mathrm{Ti}_{2}(\mathrm{Hbdha})_{2}\left(\mathrm{H}_{2} \mathrm{bdha}\right)\right]$ directed by the interlayer $\mathrm{H}$-bonds. (c) Helical chains assembled from $\mathrm{H}$-bonded alternated hydroxamate titanium chelates viewed along [100] and [001]. (d) Perspective of MUV-11 along the $c$ axis showing the Connolly representation of the $1 \mathrm{D}$ channels with triangular shape responsible for the porosity in the solid (pale blue, $1.2 \AA$ probe radius). Hydrogen atoms and solvent molecules have been omitted for clarity.

presume the corrugated structure of the layers and H-bond interactions are responsible for the packing of the solid. Compared to NTU-9, which displays an …AA eclipsed packing, MUV-11 combines three types of neutral $\left[\mathrm{Ti}_{2}(\mathrm{Hbdha})_{2}\left(\mathrm{H}_{2}\right.\right.$ bdha $\left.)\right]$ layers arranged in a $\cdots \mathrm{ABC} \cdots$ fashion for an overall slipped packing. Similar to NTU-9, ${ }^{30}$ a fraction of the hydroxamic NH- groups in the linker must be deprotonated to account for the neutrality of the framework. MUV-11 might be also formulated as $\left[\mathrm{Ti}_{2}(\mathrm{Hbdha})_{2.67}\right]$, in which all linkers would be structurally equivalent and partially double-deprotonated for charge neutrality. As shown in Figure 2c, the structure of MUV-11 displays helical chains built from the $\mathrm{H}$-bonding of alternating five-membered hydroxamate chelates $(-\mathrm{Ti}-\mathrm{O}-\mathrm{N}-\mathrm{C}=\mathrm{O}-$ ) along [001]. This helix is further bridged by the organic linker to the adjacent chains. As shown in Figure $2 \mathrm{~d}$, the helical-like packing results in the formation of empty 1D channels along [001] with a pseudohexagonal shape and internal diameter of $0.8 \mathrm{~nm}$, which account for a solvent-accessible volume close to $40 \%$ (Table S8) and a theoretical surface area near $950 \mathrm{~m}^{2} \cdot \mathrm{g}^{-1}$ as estimated with $\mathrm{Zeo}++.^{28}$ All helical chains display the same handedness for overall chirality at a single-crystal level, consistent with the chiral space group $P 3_{2}$. Chiral dichroism measurements (Figure S23) do not show significant optical activity, suggesting that the solid isolated contains an equimolar mixture of both enantiomers.

High-Throughput Screening of Other Metal Precursors. Possibly one of the most important requirements to access crystalline Ti-MOFs is to gain control over the hydrolytic stability of the metal precursor under frameworkforming conditions to prevent the formation of amorphous titanium oxide. Besides the use of preformed clusters, ${ }^{15,17,19,23}$ this is arguably the reason for which most materials have been produced by using primarily titanium(IV) isopropoxide (TTIP), i.e., MIL-177,, ${ }^{20}$ MIL-168,169, ${ }^{26}$ MIL-125, ${ }^{14}$ TiCAT-5, ${ }^{24}$ MOF-902, ${ }^{17}$ NTU-9, ${ }^{31}$ or MUV- $10^{21}$ and bis(cyclopentadienyl)titanium(IV) dichloride (BCTTD) for COK-69. ${ }^{32}$ Enlarging the pool of precursors compatible with solvothermal synthesis might help accelerate the discovery of new titanium-organic frameworks. This pushed us to investigate the synthesis of MUV-11 by using other affordable $\mathrm{Ti}$ salts with variable reactivity in water. Accordingly, we replaced TTIP in the original synthesis with six other precursors including BCTTD, cyclopentadienyltitanium(IV) trichloride (CTTT), titanium(IV) $n$-propoxide (TTP), titanium(IV) n-butoxide (TTB), titanium(IV) 2-ethylhexyloxide (TTEEO), and titanium(IV) triethanolaminato)isopropoxide (TTTEI) (Table S1).

We used a FLEX SHAKE high-throughput workstation from Chemspeed for robotic dispensing of solids and liquids in order to accelerate the screening and systematic study of the multiple variables in play (temperature, reaction time, solvent, concentration, and modulator) to define the best set of conditions for the synthesis of crystalline MUV-11 regardless of the precursor, while ensuring reproducibility. See Section S3 for a detailed description of all the variations explored. Our experiments confirm that phase-pure MUV-11 can also be prepared from TTP, TTB, and TTTEI with yields between $50 \%$ and $70 \%$. The use of TTEEO and organometallic precursors (BCTTD and CTTT) yielded amorphous phases in all cases. We used scanning electron microscopy (SEM) and PXRD to evaluate the effect of the precursor over the particle size and crystallinity of the material (Figure 3). All solids crystallize as lamellae particles with hexagonal morphology. Their average size increases from 5 to $50 \mu \mathrm{m}$ according to the sequence TTP < TTIP < TTB < TTTEI. This last precursor also drives the formation of the most crystalline MUV-11 phase. Just like for sol-gel processing, our results suggest that the modification of the titanium alkoxide with multidentate $-\left(\mathrm{OC}_{4} \mathrm{H}_{4}\right)_{3} \mathrm{~N}$ linkers in TTTEI helps control its reactivity in the presence of water. ${ }^{33}$ This chelate is less readily hydrolyzed than -OR groups in the conditions required for the crystallization of the framework, thus preventing the rapid formation of amorphous materials.

Porosity and Chemical Stability. The best product in terms of yield, homogeneity, and crystal size was obtained by using TTTEI. As summarized in Section S5, phase purity of the batch was confirmed by CHN analysis, SEM, LeBail refinement of the powder X-ray diffraction, and thermogravimetric analysis (TGA). On the basis of CHN we determine a 

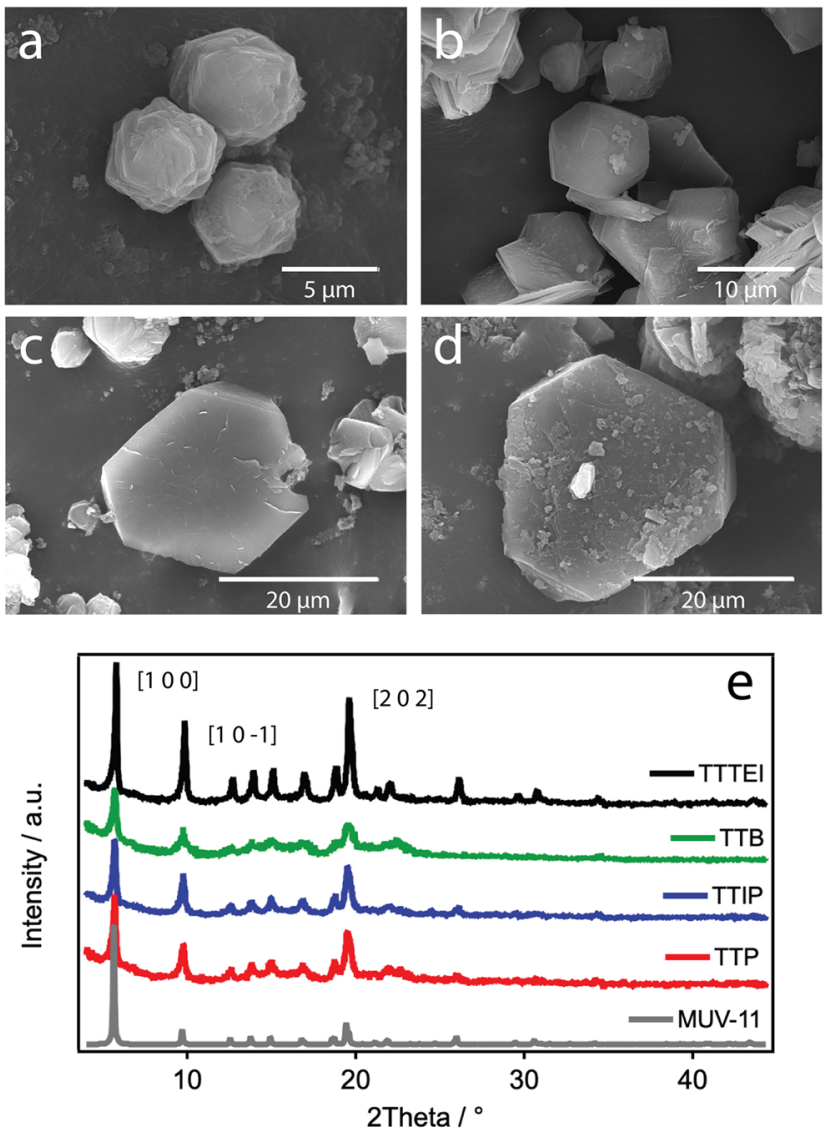

Figure 3. Effect of the $\mathrm{Ti}(\mathrm{IV})$ precursor used in the synthesis of MUV-11 over the morphology and size of the particles formed: (a) TTP, (b) TTIP, (c) TTB, (d) TTTEI, and (e) changes to the crystallinity of the framework.

unit formula of $\left[\mathrm{Ti}_{2}(\mathrm{Hbdha})_{2}\left(\mathrm{H}_{2} \mathrm{bdha}\right)\right] \cdot(\mathrm{DMF})_{0.5} \cdot\left(\mathrm{H}_{2} \mathrm{O}\right)_{3.3}$ for the as-made solid. TGA of the desolvated material is consistent with the $23.1 \%$ of residual $\mathrm{TiO}_{2}$ formed (calcd 23.6\%). MUV-11 displays a thermal stability similar to other Ti-MOFs. As expected from the formation of thermodynamically strong $\mathrm{Ti}-\mathrm{O}$ coordination bonds, complete decomposition takes place above $400{ }^{\circ} \mathrm{C}$. However, there is significant mass loss at $240{ }^{\circ} \mathrm{C}$ that might be linked to the partial decomposition of bdha units, more prone to oxidation than carboxylate linkers (Figure S21).

Porosity was studied by $\mathrm{N}_{2}$ adsorption-desorption isotherms at $77 \mathrm{~K}$ after exchanging the as-made solid with acetone, followed by activation at $100{ }^{\circ} \mathrm{C}\left(10^{-3} \mathrm{mbar}\right)$. MUV11 displays a reversible type-I $\mathrm{N}_{2}$ adsorption characteristic of microporous materials, with a small hysteresis above $P / P_{0}=$ 0.4 indicative of intergrain mesoporosity (Figures $4 \mathrm{a}$ and S26). The multipoint BET surface area was found to be $756 \mathrm{~m}^{2} \cdot \mathrm{g}^{-1}$. Analysis of the pore size distribution (PSD) by using nonlinear density functional theory (NLDFT) methods reveals a homogeneous pore diameter of $1.0 \mathrm{~nm}$, which agrees well the $0.8 \mathrm{~nm}$ calculated from the structure. We also confirmed the porosity of the solid with $\mathrm{CO}_{2}$. MUV-11 displays a reversible type-I isotherm at $195 \mathrm{~K}$ with less abrupt adsorption at low pressures (Figure S28). At high temperatures, it displays a modest gravimetric uptake of $1.23 \mathrm{mmol} \cdot \mathrm{g}^{-1}$ of $\mathrm{CO}_{2}$ at $293 \mathrm{~K}$ and $1 \mathrm{bar}(5.4 \mathrm{wt} \%)$, with an isosteric heat of adsorption of $29.9 \mathrm{~kJ} \cdot \mathrm{mol}^{-1}$ (Figure S29). Similar to the introduction of

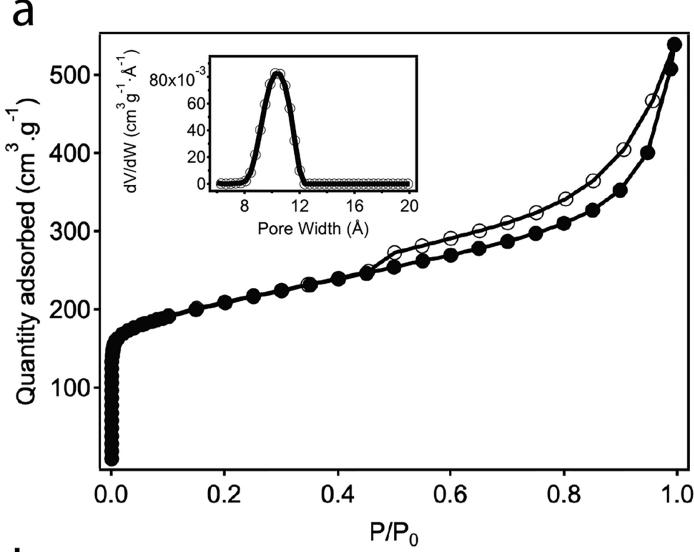

b

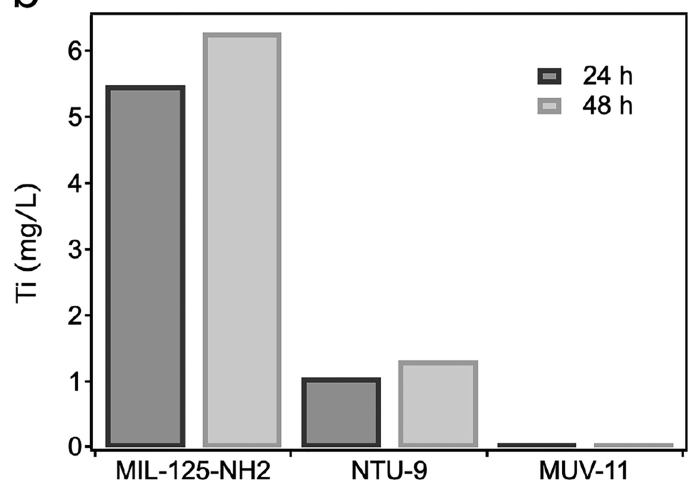

Figure 4. (a) $\mathrm{N}_{2}$ adsorption at $77 \mathrm{~K}$ of MUV-11 exchanged with acetone. Inset shows the experimental PSD. (b) Ti concentration values determined by ICP-MS of the supernatant after soaking in aqueous solution at $\mathrm{pH} 2$ for 24 and $48 \mathrm{~h}$.

amino groups, replacement of carboxylic groups with nitrogenated hydroxamate $-\mathrm{CONHO}^{-}$units seems responsible for more favorable interaction of $\mathrm{CO}_{2}$ molecules with the surface of the pores. It is worth noting that the structure of MUV-11 is quite sensitive to the activation protocol employed. Soxhlet washing of the solid with protic solvents led to partial collapse of the structure for a substantial reduction of accessible porosity (Figure S26). This is likely due to the network of $\mathrm{H}$ bonds that directs interlayer packing and thereby dictates the 3D structure of MUV-11 (Figure 2b). Compared with solvents such as acetone, not capable of $\mathrm{H}$-bonding, solvent exchange with methanol results in partial amorphization likely due to a disordered reorganization of interlayer interactions.

We evaluated the chemical stability of MUV-11 after immersion of the solid for hours in concentrated solutions of $\mathrm{HCl}$ and $\mathrm{NaOH}(\mathrm{aq})$ between $\mathrm{pH} 1$ and 14. The PXRD of the solids recovered confirm retention the diffraction lines characteristic of the solid together with a partial amorphization of the framework, likely linked to the distortion of interlayer packing interactions by interaction with water (Section S6). We also investigated the effect of hydroxamic connectors over the chemical stability of MUV-11 in comparison to other TiMOFs based on carboxylate linkers such as terephthalic acid (MIL-125- $\mathrm{NH}_{2}$ ) and dhtp (NTU-9). ICP-MS analysis of the supernatants of the solids after incubation at $\mathrm{pH} 2$ for 24 and $48 \mathrm{~h}$ shows negligible metal leaching for MUV-11 (Figure $4 \mathrm{~b}$ ). In turn, the concentration of titanium in solution increases with time up to a maximum of 6.3 and $1.3 \mathrm{mg} \cdot \mathrm{mL}^{-1}$ for MIL$125-\mathrm{NH}_{2}$ and NTU-9, respectively, after $48 \mathrm{~h}$. Compared to 

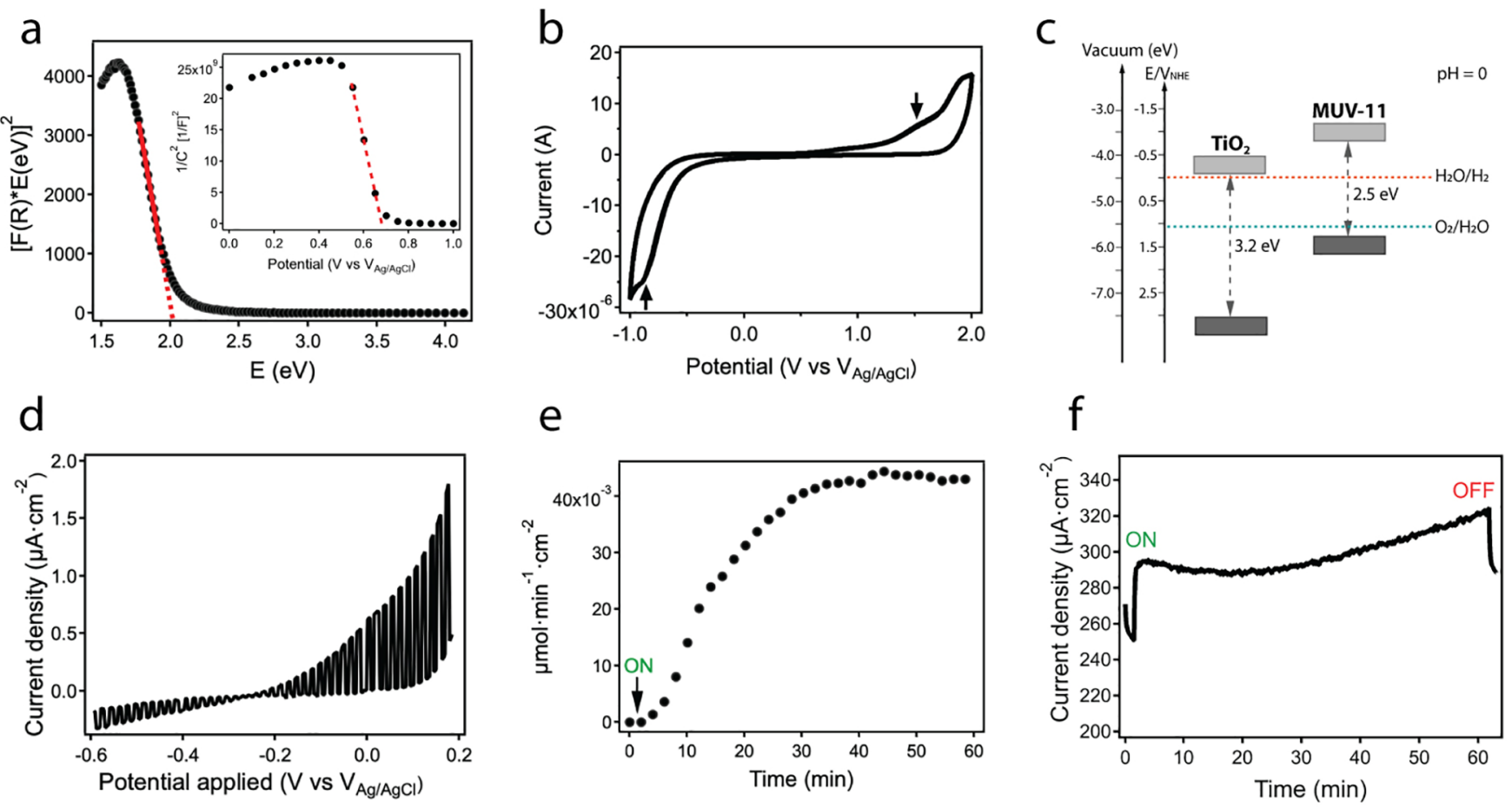

Figure 5. Optical, electrochemical, and photoelectrochemical properties of MUV-11. (a) Tauc plot of the solid by Kubelka-Munk approximation showing a direct optical band gap of $2.0 \mathrm{eV}$. Inset: Mott-Schotkky plot at $400 \mathrm{~Hz}$ with a flat-band potential of $0.68 \mathrm{~V}$. (b) Cyclic voltammogram of MUV-11 in nonaqueous electrolyte at $20 \mathrm{mV} / \mathrm{s}$ scan rate. (c) Experimental energy diagram showing the alignment of HOMO and LUMO of MUV-11 with the band edges of $\mathrm{TiO}_{2}$ and the water splitting redox couples at $\mathrm{pH}=0$. (d) Photocurrent density collected under chopped illumination showing the response at different bias potentials. (e) Hydrogen evolution under chopped $\mathrm{AM} 1.5$ illumination at $0.5 \mathrm{~V}$ vs $\mathrm{Ag} / \mathrm{AgCl}$ and (f) chronoamperometric response recorded simultaneously. See S7 for experimental details.

the performance in acid media of other mesoporous solids with excellent chemical stability like MIL-101(Cr) ${ }^{7}$ or MIL-100(Fe, $\mathrm{Ti}),{ }^{6,23}$ MUV-11 also displays minimum leaching to confirm high resistance toward hydrolysis in these conditions (Figure S34, Table S9). Chemical stability was further corroborated with ${ }^{1} \mathrm{H}$ NMR to discard linker leaching under these conditions (Figure S35, Table S10). We presume that the differences in the degradation rates of the solids are controlled by the changes in the stability constants for complex formation, higher for dhtp and bdha as result of the formation of fivemembered chelates. Anionic hydroxamates are known to form hard oxo donors that bind strongly to Lewis acids, resulting in complexes with remarkably high stability constants. ${ }^{34}$ Our results confirm that these strong metal joints are capable of preventing chemical degradation to endow MUV-11 with good stability in acid medium. It is instead the structural flexibility intrinsic to the interlayer packing in the solid that directs structural changes for the collapse of this particular framework.

Electronic Structure and Photoelectrochemical Response. The use of Ti-MOFs as photocatalysts for solar fuel production or light-induced organic transformations is gaining importance due to the combination of high surface areas and chemical stability with the redox versatility and photoactivity intrinsic to titanium. ${ }^{35}$ As shown in Figure 5a, the Tauc plot obtained through the diffuse reflectance spectra of MUV-11 confirms a broad absorption in the visible region from 300 to $550 \pm 10 \mathrm{~nm}$. An optical band gap energy of $2.01 \pm 0.01 \mathrm{eV}$ was calculated through the Kubelka-Munk function. This value is smaller than those reported for COK-69 (3.77 eV), MIL-125 (3.6 eV), MUV-10(Ca) (3.1 eV), MOF-901 (2.65
$\mathrm{eV}$ ), and MIL-125- $\mathrm{NH}_{2}(2.6 \mathrm{eV})$ while slightly above PCN-22 $(1.93 \mathrm{eV})$ and NTU-9 $(1.72 \mathrm{eV})$.

For a clearer understanding of the electronic structure of MUV-11 we prepared electrodes by drop casting a suspension of the MOF on the ITO cover glasses (Section S7). Electrochemical impedance spectroscopy (EIS) and cyclic voltammetry $(\mathrm{CV})$ measurements were used to estimate the flat band potential and determine the absolute positions of the valence and conduction band edges in MUV-11 (Figures 5a,b). The Mott-Schotky plot confirms that MUV-11 displays p-type conductivity with a flat-band potential of $0.68 \pm 0.02 \mathrm{~V}$ vs Ag/ $\mathrm{AgCl}$ or $0.48 \pm 0.02 \mathrm{~V}$ vs the normal hydrogen electrode (NHE). The CV of MUV-11 films in a nonaqueous electrolyte $\left(0.1 \mathrm{M} \mathrm{NBu}_{4} \mathrm{PF}_{6}\right.$ in acetonitrile) shows the presence of anodic and cathodic peaks at -0.8 and $1.6 \mathrm{~V}$ vs $\mathrm{Ag} / \mathrm{Ag}^{+}$, which was later corrected with the ferrocene couple. This experimental information was used to calculate the approximate positions of the HOMO and LUMO energies at -6.1 and $-3.6 \pm 0.1 \mathrm{eV}$. Figure $5 \mathrm{c}$ shows the comparison of the absolute energies of the HOMO and LUMO in MUV-11 with $\mathrm{TiO}_{2}$ and the redox pairs for the hydrogen evolution reaction $\left(\mathrm{HER}, \mathrm{H}_{2} \mathrm{O} / \mathrm{H}_{2}\right.$ ) and oxygen evolution reaction $\left(\mathrm{OER}, \mathrm{O}_{2} / \mathrm{H}_{2} \mathrm{O}\right)$ at $\mathrm{pH}=0$. The LUMO is higher in energy than $\mathrm{H}_{2} \mathrm{O} / \mathrm{H}_{2}$, and the $\mathrm{HOMO}$ is lower than $\mathrm{O}_{2} / \mathrm{H}_{2} \mathrm{O}$ in acid conditions, for which the MOF displays outstanding chemical stability. This suggests that, in principle, MUV-11 would be thermodynamically suitable for photocatalytic water splitting reactions.

We tested the photoelectrochemical activity of MUV-11 films by using the MOF as the working electrode in a threeelectrode configuration cell in an argon-purged aqueous electrolyte $\left(0.5 \mathrm{M}, \mathrm{Na}_{2} \mathrm{SO}_{3}\right.$ in water $)$ with a solar simulator 
(AM 1.5) as illumination source. Figure 5d shows the chopped-light photocurrent density response at different bias potentials between -0.6 and $0.2 \mathrm{eV}$ vs $\mathrm{Ag} / \mathrm{AgCl}$, confirming good light absorption for the whole range of potentials studied. Next, we connected the cell to a gas chromatograph and illuminated the films at different bias potentials to evaluate photocatalytic HER. As shown in Figure 5e, MUV-11 photoelectrodes display a sigmoidal hydrogen production rate at $0.5 \mathrm{~V}$ vs $\mathrm{Ag} / \mathrm{AgCl}$ that reaches a plateau after $40 \mathrm{~min}$. The experiment was performed for $1 \mathrm{~h}$ with simultaneous measurement of the photogenerated current. The current density values obtained during the HER remain quite steady, oscillating around $300 \pm 20 \mu \mathrm{A} \cdot \mathrm{cm}^{2}$ (Figure $5 \mathrm{f}$ ). We did not observe any signal decay during the experiment that might be indicative of photocorrosion or passivation of the solid, confirming the excellent stability of MUV-11 in these conditions.

We next tested the activity of the solid without electrical polarization by irradiating a suspension of the solid in $\mathrm{H}_{2} \mathrm{O}: \mathrm{MeOH}(4: 1 \mathrm{v} / \mathrm{v} \%)$ with a solar simulator (Figure 6).

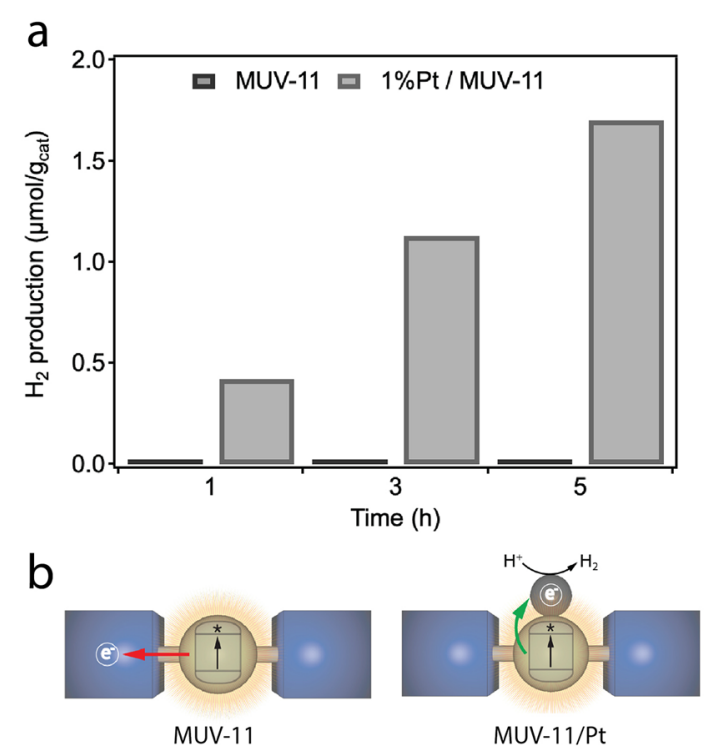

Figure 6. (a) Hydrogen production of MUV-11 and 1\% Pt/MUV-11 at 1,3 , and $5 \mathrm{~h}$ of illumination with a solar simulator. (b) The inactivity of MUV-11 for the HER suggests inefficient charge separation in the absence of an applied electrical field (left) that can be overcome by addition of Pt as cocatalyst (right).

MUV-11 did not produce measurable amounts of $\mathrm{H}_{2}$ after $5 \mathrm{~h}$ of irradiation. In turn, after co-deposition of 1 wt $\%$ of platinum as cocatalyst, Pt/MUV-11 displayed a linear production of $\mathrm{H}_{2}$ for a total of $1.7 \mu \mathrm{mol} \cdot \mathrm{g}^{-1}$ in the same period. No $\mathrm{H}_{2}$ was produced in the dark, confirming the photocatalytic nature of the reaction. PXRD and IR spectra of MUV-11 and Pt/MUV-11 were used to confirm the stability of the material after the photocatalytic experiments (Figure S41). Chemical degradation was discarded by ICP-MS of the supernatant in these conditions (Figure S39). MUV-11 displays very small $\mathrm{H}_{2}$ production compared to the values reported for other carboxylate $\mathrm{Ti}-\mathrm{MOF}$ in these conditions such as MUV-10(Ca, Mn $)^{21}$ or MIL-100(Ti). ${ }^{23}$ As shown in Figure S37, the use of alternative sacrificial donors such as TEOA (triethanolamine) or $\mathrm{CH}_{3} \mathrm{CN}$ :TEA: $\mathrm{H}_{2} \mathrm{O}$ (TEA, triethylamine) also resulted in very poor performance compared to materials such as MIL-125- $\mathrm{NH}_{2}$ or MIL-167 under equivalent conditions (Table S11). ${ }^{26,36,37}$ Photocatalytic performance is not improved when MUV-11 is prepared from other titanium precursors (Figure S38). These results confirm the ability of MUV-11 to behave as a hydrogen production photocatalyst but also highlight its poor performance and the necessity of using $\mathrm{Pt}$ as a cocatalyst to favor $\mathrm{H}_{2}$ production in the absence of an applied potential acting as a driving force. Since MUV-11 combines good chemical stability with suitable band gap and band edge potentials to tackle this reaction, we decided to investigate if the photocatalytic efficiency in this hydroxamic MOF might be governed by other parameters.

Effect of the Organic Connector over Photocatalytic Activity. We calculated the electronic structure of MUV-11 and other representative photocatalytic Ti-MOFs for a better understanding of the experimental results. Figure $7 \mathrm{a}$ shows
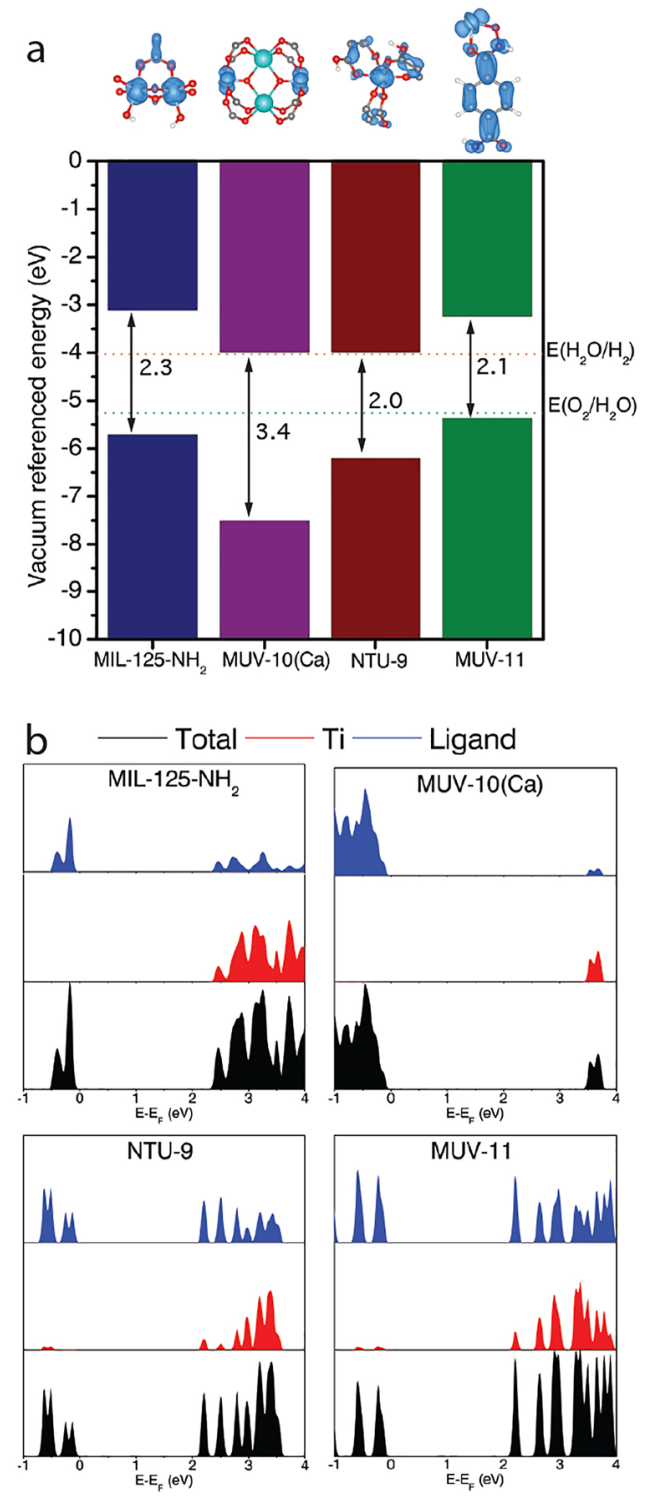

Figure 7. (a) Electronic band alignment relative to the vacuum level and the water oxidation/reduction potentials at $\mathrm{pH}=7$ (dot lines) for selected Ti-MOFs. Orbitals contributing to the LUCO (top). (b) Total (black) and projected ( $\mathrm{Ti}$ in red and ligand in blue) density of states for MIL-125-NH 2 , MUV-10(Ca), NTU-9, and MUV-11. 
calculated energy levels and band gaps of MIL-125- $\mathrm{NH}_{2}(2.3$ eV), MUV-10(Ca) (3.4 eV), NTU-9 $(2.0 \mathrm{eV})$, and MUV-11 $(2.1 \mathrm{eV})$, all compatible with visible-light photoactivity. From a purely thermodynamic point of view, the position of the edge of the lowest unoccupied crystalline orbital (LUCO) relative to the $\mathrm{H}_{2} \mathrm{O} / \mathrm{H}_{2}$ pair ( $\mathrm{pH}=7$, room temperature) is expected to control the turnover for the HER. According to our calculations, the four materials would be thermodynamically suitable for photocatalytic HER with a better performance for NTU-9 and MUV-10(Ca), followed by MIL-125- $\mathrm{NH}_{2}$ and MUV-11 with LUCOs slightly higher in energy. However, this contradicts their experimental performance and the calculated orbital contributions to the LUCO, which are almost exclusively centered in the titanium for MIL-125- $\mathrm{NH}_{2}$ and MUV-10(Ca), whereas electron density is delocalized between $\mathrm{Ti}$ and the organic linker orbitals in NTU-9 and MUV-11 (Figures 7a top and S44). Overall, this suggests that the thermodynamic picture is too simple and there must be additional factors governing the photocatalytic performance of MUV-11. We must also consider the kinetics of charge transfer upon illumination.

Efficient charge separation is needed to prevent the fast recombination of the photogenerated charge carriers in order to prolong the lifetime of the excited states. ${ }^{38}$ MOFs in which charge separation involves ligand-to-metal charge transfer (LMCT) are arguably more adequate for photocatalytic purposes than others in which the excited state is localized in isolated linkers or metals. Titanium frameworks built from carboxylic acids such as terephthalate (MIL-125- $\mathrm{NH}_{2}$ ) and trimesate (MUV-10(Ca)) undergo LMCT with illumination, as confirmed by the presence of photoreduced $\mathrm{Ti}^{3+}$ in the electron paramagnetic resonance (EPR) spectra of the irradiated solids. $^{21,39,40}$ This behavior agrees well with their calculated electronic density of states (DOS) diagram (Figures $7 \mathrm{~b}$ and S43). The highest occupied crystalline orbital (HOCO) of these frameworks is localized at the organic linker, whereas the LUCO is centered on the titanium region. They present a negative ligand-to metal charge-transfer energy $\left(E_{\mathrm{LMCT}}\right)$, which is defined as the energy change upon transferring an electron from the photoexcited linker orbital to the lower unoccupied metal ion orbital. ${ }^{41}$ In turn, MUV-11 and NTU-9, built from hydroxamic and hydroxycarboxylic siderophore metal binders, display LUCOs located simultaneously at the organic linker and the metal. The calculated contribution to the density of states at the conduction band suggests that carboxylic MOFs are mainly localized at the metal, whereas siderophores are instead centered at the linker, with a contribution close to $70 \%$ (Table S12). This change in the electronic structure of the frontier orbitals is less likely to induce LMCT for short-lived excitons localized at the organic linker, consistent with positive $E_{\mathrm{LMCT}}$ values close to zero. The poor photocatalytic performance of MUV-11 seems to be kinetic in origin. Even though its thermodynamic energy alignment is compatible with water reduction, the poor efficiency of LMCT will produce single-electron-localized photoexcited states, unable to migrate and reduce the metal nodes for the formation of photocatalytic $\mathrm{Ti}^{3+}$ species. Our theoretical findings are consistent with the EPR spectrum of MUV-11 after illumination. We did not observe the occurrence of any paramagnetic signal that could account for the formation of photogenerated $\mathrm{Ti}^{3+}$ species (Figure S42). These results are consistent with recent reports ${ }^{42,43}$ that highlight the importance of orbital contributions at the band edges in controlling LMCT and thereby the photocatalytic efficiency of UiO-type MOFs with the introduction of different $\mathrm{d}^{0}$ metals (Ti, Zr, Hf, Ce, Th, or U). Our results suggest that not only the unoccupied bands of the metallic nodes but also the metal binding group and the chemistry of this particular type of linkers can introduce changes to the electronic structure of the frontier orbitals in these solids also relevant to their function.

\section{CONCLUSIONS}

The design of chemically stable MOFs, and more particularly titanium-organic frameworks, is still restricted to a limited group of metal connectors. We report for the first time the ability of hydroxamic acids to produce reticular solids by de novo synthesis. MUV-11 is a crystalline, porous material that combines photoactivity with outstanding chemical stability in acid conditions intrinsic to the introduction of siderophore metal binders. Compared to other carboxylate Ti frameworks, this hydroxamate MOF can be prepared as single-crystalline phases for multiple titanium salts, thus expanding the scope of precursors accessible to this chemistry. We make use of photoelectrochemical and catalytic studies to compare the electronic structure and photoactivity of MUV-11 with other selected materials such as MIL-125- $\mathrm{NH}_{2}, \mathrm{MUV}-10(\mathrm{Ca})$, and NTU-9. Computational modeling reveals striking differences in the charge separation kinetics of the MOFs built from siderophores. These are less likely to undergo photostimulated LMCT for generating active $\mathrm{Ti}^{3+}$ species as a result of the delocalization of the electronic density delocalized between the metal node and the organic linker. Provided the principles of isoreticular chemistry, the straightforward derivatization of carboxylic linkers with hydroxamic groups might represent an alternative synthetic platform for the synthesis of crystalline titanium MOFs. We hope this combination of experiment and theory will help delineate future directions in this context.

We are confident this work might as well offer new perspectives for the chemistry of covalent organic frameworks (COFs). The critical step in the crystallization of COFs is to reach synthetic conditions that enable reversible formation of covalent bonds between building blocks to enable defect repair during crystal growth. ${ }^{44,45}$ Either by direct condensation or controlled hydrolysis of hydroxamic acid connectors into carboxylic acids, these linkers might help in gaining control over covalent bond formation and inspire similar approaches to grow COF crystals.

\section{EXPERIMENTAL SECTION}

Synthesis of MUV-11. $\mathrm{H}_{4}$ bdha $(70.6 \mathrm{mg} ; 0.36 \mathrm{mmol}$ ) was suspended in a mixture of $7.2 \mathrm{~mL}$ of $\mathrm{N}, \mathrm{N}$-dimethylformamide and 2.1 $\mathrm{mL}$ of $\mathrm{AcOH}$ in a $25 \mathrm{~mL}$ Schott bottle. Subsequently, $72 \mu \mathrm{mol}$ of the titanium precursor was added to the suspension. The bottle was sealed and heated in an oven at $120{ }^{\circ} \mathrm{C}$ for $48 \mathrm{~h}$. After cooling to room temperature, this results in the formation of hexagonal orange crystals that were isolated by filtration and rinsed with $45 \mathrm{~mL}$ of DMF $(3 \times 15 \mathrm{~mL})$ and $45 \mathrm{~mL}$ of acetone $(3 \times 15 \mathrm{~mL})$. The product was dried at room temperature.

Photoelectrochemical Measurements. Experiments were performed in a three-electrode glass cell with a quartz window containing an aqueous solution of $0.5 \mathrm{M}$. MUV-11 powder suspensions were deposited by drop casting on indium tin oxide (ITO) cover glasses and used as working electrode. The counter electrode was a platinum wire, and the reference one was an $\mathrm{Ag} / \mathrm{AgCl}$ electrode. Voltage, current density (at dark and under illumination), and electrochemical impedance spectroscopy were measured with a 
potentiostat-galvanostat PGSTAT204 provided with an integrated impedance module FRAII ( $10 \mathrm{mV}$ of modulation amplitude is used at $400 \mathrm{~Hz}$ ). A solar simulator (LOT LSH302 Xe lamp and an LSZ389 AM1.5 global filter) was used as a light source.

Photocatalytic Experiments. The photocatalytic activity of MUV-11 for $\mathrm{H}_{2}$ evolution was performed by irradiating a dispersion of $1 \mathrm{mg} / \mathrm{mL}$ of the MOF in $\mathrm{H}_{2} \mathrm{O}: \mathrm{MeOH}$ solutions $(4: 1 \mathrm{v} / \mathrm{v} \%)$ in sealed vessels, purged with Ar. As-made MUV-11 was activated under vacuum before purging with $\mathrm{N}_{2}$. Pt was added in the dark as an aqueous solution of $\mathrm{H}_{2} \mathrm{PtCl}_{6}$ (1 wt \%) before purging for in situ photodeposition upon illumination. The suspension was kept under constant stirring and irradiated with a solar simulator $(253 \mathrm{~W})$ at room temperature. The formation of gases in the liquid phase was detected with a PerkinElmer (Clarus 580GC) gas chromatograph equipped with a TCD detector.

Computational Details. All calculations were performed with periodic density functional theory by using the Vienna ab Initio Simulation Package. ${ }^{46,47}$ For the geometry optimizations, we used the generalized gradient approximation with the Perdew-BurkeErnzerhof functional ${ }^{48}$ and including van der Waals corrections via the DFT-D3 method of Grimme. ${ }^{49,30}$ The kinetic energy cutoff for the plane-wave basis set expansion was chosen as $500 \mathrm{eV}$, and $\Gamma$ points were used for integrations in the reciprocal space, due to the large size of the unit cell of the direct lattice. Finally, the total DOS and the electronic band structure of the crystalline solids were calculated by using the screened hybrid functional of Heyd, Scuseria, and Ernzerhof (HSE06). ${ }^{51}$ The electron energies were aligned to the vacuum level using a procedure reported by Butler and co-workers. ${ }^{52}$

\section{ASSOCIATED CONTENT}

\section{S Supporting Information}

The Supporting Information is available free of charge on the ACS Publications website at DOI: 10.1021/jacs.9b04915.

Synthetic and experimental details; physical characterization and supporting tables and figures (PDF)

X-ray crystallographic data for MUV-11 (CIF)

\section{AUTHOR INFORMATION}

\section{Corresponding Author}

*carlos.marti@uv.es

\section{ORCID $\odot$}

Natalia M. Padial: 0000-0001-6067-3360

Javier Castells-Gil: 0000-0001-7931-3867

Neyvis Almora-Barrios: 0000-0001-5269-2705

Mariam Barawi: 0000-0001-5719-9872

Víctor A. de la Peña O'Shea: 0000-0001-5762-4787

Carlos Martí-Gastaldo: 0000-0003-3203-0047

\section{Present Address}

${ }^{\ddagger}$ Department of Chemistry, Scripps Research, 10550 North Torrey Pines Road, La Jolla, California 92037, United States.

\section{Author Contributions}

${ }^{\perp}$ N. M. Padial and J. Castells-Gil contributed equally.

\section{Notes}

The authors declare no competing financial interest. CCDC 1884457 contains the supplementary crystallographic data for this paper.

\section{ACKNOWLEDGMENTS}

This work was supported by the EU (ERC Stg Chem-fs-MOF 714122, ERC CoG HyMAP 648319) and Spanish MINECO (MDM-2015-0538, CTQ2017-83486-P, and ENE2016-79608C2-1-R). C.M.-G., N.M.P., J.C.-G., and M.B. thank the Spanish MINECO for a Ramón y Cajal Fellowship (RYC-2012-10894),
Marie Skłodowska Curie Fellowship (H2020-MSCA-IF-2016GF-749359-EnanSET), FPI Scholarship (CTQ2014-59209-P), and Juan de la Cierva Fellowship (FJCI-2016-30567), respectively. We thank ALBA Facilities for the access to synchrotron radiation at beamlines XALOC and MSPD and BSC-RES for computational resources (QCM-2019-1-0042). Dr. A. R. Ruiz-Salvador is acknowledged for technical help.

\section{REFERENCES}

(1) Furukawa, H.; Cordova, K. E.; O’Keeffe, M.; Yaghi, O. M. The Chemistry and Applications of Metal-Organic Frameworks. Science 2013, 341 (6149), 1230444.

(2) Colombo, V.; Galli, S.; Choi, H.; Han, G.; Maspero, A.; Palmisano, G.; Masciocchi, N.; Long, J. R. High Thermal and Chemical Stability in Pyrazolate-Bridged Metal-Organic Frameworks with Exposed Metal Sites. Chem. Sci. 2011, 2 (7), 1311-1319.

(3) Park, K.; Ni, Z.; Côté, A.; Choi, J.; Huang, R.; Uribe-Romo, F.; Chae, H.; O'Keeffe, M.; Yaghi, O. M. Exceptional Chemical and Thermal Stability of Zeolitic Imidazolate Frameworks. Proc. Natl. Acad. Sci. U. S. A. 2006, 103 (27), 10186-10191.

(4) Lv, X.-L.; Wang, K.; Wang, B.; Su, J.; Zou, X.; Xie, Y.; Li, J.-R.; Zhou, H.-C. A Base-Resistant Metalloporphyrin Metal-Organic Framework for C-H Bond Halogenation. J. Am. Chem. Soc. 2017, 139 (1), 211-217.

(5) Serre, C.; Millange, F.; Thouvenot, C.; Noguès, M.; Marsolier, G.; Louër, D.; Ferey, G. Very Large Breathing Effect in the First Nanoporous Chromium(III)-Based Solids: MIL-53 or $\operatorname{CrIII}(\mathrm{OH})$. $\{\mathrm{O} 2 \mathrm{C}-\mathrm{C} 6 \mathrm{H} 4-\mathrm{CO} 2\} \cdot\{\mathrm{HO} 2 \mathrm{C}-\mathrm{C} 6 \mathrm{H} 4-\mathrm{CO} 2 \mathrm{H}\} \mathrm{x} \cdot \mathrm{H} 2 \mathrm{Oy}$. J. Am. Chem. Soc. 2002, 124 (45), 13519-13526.

(6) Ferey, G.; Serre, C.; Mellot-Draznieks, C.; Millange, F.; Surblé, S.; Dutour, J.; Margiolaki, I. A Hybrid Solid with Giant Pores Prepared by a Combination of Targeted Chemistry, Simulation, and Powder Diffraction. Angew. Chem., Int. Ed. 2004, 43 (46), 62966301.

(7) Ferey, G.; Mellot-Draznieks, C.; Serre, C.; Millange, F.; Dutour, J.; Surblé, S.; Margiolaki, I. A Chromium Terephthalate-Based Solid with Unusually Large Pore Volumes and Surface Area. Science 2005, 309 (5743), 2040-2042.

(8) Cavka, J.; Jakobsen, S.; Olsbye, U.; Guillou, N.; Lamberti, C.; Bordiga, S.; Lillerud, K. A New Zirconium Inorganic Building Brick Forming Metal Organic Frameworks with Exceptional Stability. J. Am. Chem. Soc. 2008, 130 (42), 13850-13851.

(9) Devic, T.; Serre, C. High Valence 3p and Transition Metal Based MOFs. Chem. Soc. Rev. 2014, 43 (16), 6097-6115.

(10) Bai, Y.; Dou, Y.; Xie, L.-H.; Rutledge, W.; Li, J.-R.; Zhou, H.-C. Zr-Based Metal-Organic Frameworks: Design, Synthesis, Structure, and Applications. Chem. Soc. Rev. 2016, 45 (8), 2327-2367.

(11) Howarth, A. J.; Liu, Y.; Li, P.; Li, Z.; Wang, T. C.; Hupp, J. T.; Farha, O. K. Chemical, Thermal and Mechanical Stabilities of MetalOrganic Frameworks. Nat. Rev. Mater. 2016, 1 (3), 15018.

(12) Yuan, S.; Qin, J.-S.; Lollar, C. T.; Zhou, H.-C. Stable MetalOrganic Frameworks with Group 4 Metals: Current Status and Trends. ACS Cent. Sci. 2018, 4 (4), 440-450.

(13) Assi, H.; Mouchaham, G.; Steunou, N.; Devic, T.; Serre, C. Titanium Coordination Compounds: From Discrete Metal Complexes to Metal-Organic Frameworks. Chem. Soc. Rev. 2017, 46 (11), 3431-3452.

(14) Dan-Hardi, M.; Serre, C.; Frot, T.; Rozes, L.; Maurin, G.; Sanchez, C.; Ferey, G. A New Photoactive Crystalline Highly Porous Titanium (IV) Dicarboxylate. J. Am. Chem. Soc. 2009, 131 (31), 10857-10859.

(15) Yuan, S.; Liu, T.-F.; Feng, D.; Tian, J.; Wang, K.; Qin, J.; Zhang, Q.; Chen, Y.-P.; Bosch, M.; Zou, L.; Teat, S. J.; Dalgarno, S. J.; Zhou, H.-C. A Single Crystalline Porphyrinic Titanium Metal-Organic Framework. Chem. Sci. 2015, 6 (7), 3926-3930.

(16) Mason, J. A.; Darago, L. E.; Jr, W. W.; Long, J. R. Synthesis and O 2Reactivity of a Titanium(III) Metal-Organic Framework. Inorg. Chem. 2015, 54 (20), 10096-10104. 
(17) Nguyen, H. L.; Gándara, F.; Furukawa, H.; Doan, T. L.; Cordova, K. E.; Yaghi, O. M. A Titanium-Organic Framework as an Exemplar of Combining the Chemistry of Metal- and CovalentOrganic Frameworks. J. Am. Chem. Soc. 2016, 138 (13), 4330-4333.

(18) Wang, C.; Liu, C.; He, X.; Sun, Z.-M. A Cluster-Based Mesoporous Ti-MOF with Sodalite Supercages. Chem. Commun. 2017, 53 (85), 11670-11673.

(19) Yuan, S.; Qin, J.-S.; Xu, H.-Q.; Su, J.; Rossi, D.; Chen, Y.; Zhang, L.; Lollar, C.; Wang, Q.; Jiang, H.-L.; Son, D. H.; Xu, H.; Huang, Z.; Zou, X.; Zhou, H.-C. $\left[\mathrm{Ti}_{8} \mathrm{Zr}_{2} \mathrm{O}_{12}(\mathrm{COO})_{16}\right]$ Cluster: An Ideal Inorganic Building Unit for Photoactive Metal-Organic Frameworks. ACS Cent. Sci. 2018, 4 (1), 105-111.

(20) Wang, S.; Kitao, T.; Guillou, N.; Wahiduzzaman, M.; Martineau-Corcos, C.; Nouar, F.; Tissot, A.; Binet, L.; Ramsahye, N.; Devautour-Vinot, S.; Kitagawa, S.; Seki, S.; Tsutsui, Y.; Briois, V.; Steunou, N.; Maurin, G.; Uemura, T.; Serre, C. A Phase Transformable Ultrastable Titanium-Carboxylate Framework for Photoconduction. Nat. Commun. 2018, 9 (1), 1660.

(21) Castells-Gil, J.; M. Padial, N.; Almora-Barrios, N.; Albero, J.; Ruiz-Salvador, R. A.; González-Platas, J.; García, H.; Martí-Gastaldo, C. Chemical Engineering of Photoactivity in Heterometallic Titanium-Organic Frameworks by Metal Doping. Angew. Chem., Int. Ed. 2018, 57 (28), 8453-8457.

(22) Keum, Y.; Park, S.; Chen, Y.-P.; Park, J. Titanium-Carboxylate Metal-Organic Framework Based on an Unprecedented Ti-Oxo Chain Cluster. Angew. Chem., Int. Ed. 2018, 238 (45), 14852-14856.

(23) Castells-Gil, J.; M. Padial, N.; Almora-Barrios, N.; da Silva, I.; Mateo, D.; Albero, J.; Garcia, H.; Martí-Gastaldo, C. De Novo Synthesis of Mesoporous Photoactive Titanium(IV)-Organic Frameworks with MIL-100 Topology. Chem. Sci. 2019, 10, 4313-4321.

(24) Nguyen, N. T.; Furukawa, H.; Gándara, F.; Trickett, C. A.; Jeong, H.; Cordova, K. E.; Yaghi, O. M. Three-Dimensional MetalCatecholate Frameworks and Their Ultrahigh Proton Conductivity. J. Am. Chem. Soc. 2015, 137 (49), 15394-15397.

(25) Gao, J.; Miao, J.; Li, P.-Z.; Teng, W.; Yang, L.; Zhao, Y.; Liu, B.; Zhang, Q. A P-Type Ti(IV)-Based Metal-Organic Framework with Visible-Light Photo-Response. Chem. Commun. 2014, 50 (29), 37863788.

(26) Assi, H.; Pérez, L. C.; Mouchaham, G.; Ragon, F.; Nasalevich, M.; Guillou, N.; Martineau, C.; Chevreau, H.; Kapteijn, F.; Gascón, J.; Fertey, P.; Elkaim, E.; Serre, C.; Devic, T. Investigating the Case of Titanium(IV) Carboxyphenolate Photoactive Coordination Polymers. Inorg. Chem. 2016, 55 (15), 7192-7199.

(27) Marmion, C. J.; Griffith, D.; Nolan, K. B. Hydroxamic Acids An Intriguing Family of Enzyme Inhibitors and Biomedical Ligands. Eur. J. Inorg. Chem. 2004, 2004 (15), 3003-3016.

(28) Pereira, C. F.; Howarth, A. J.; Vermeulen, N. A.; Paz, F. A.; Tomé, J. P.; Hupp, J. T.; Farha, O. K. Towards Hydroxamic Acid Linked Zirconium Metal-Organic Frameworks. Mater. Chem. Front. 2017, 1 (6), 1194-1199.

(29) Griffith, D.; Krot, K.; Comiskey, J.; Nolan, K. B.; Marmion, C. J. Monohydroxamic Acids and Bridging Dihydroxamic Acids as Chelators to Ruthenium(III) and as Nitric Oxide Donors: Syntheses, Speciation Studies and Nitric Oxide Releasing Investigation. Dalton Trans. 2008, 137-147.

(30) Chun, H.; Moon, D. Metal-Organic Frameworks from Group 4 Metals and 2,5-Dihydroxyterephthalic Acid: Reinvestigation, New Structure, and Challenges Toward Gas Storage and Separation. Cryst. Growth Des. 2017, 17 (4), 2140-2146.

(31) Gao, W.-Y.; Wojtas, L.; Ma, S. A Porous Metal-Metalloporphyrin Framework Featuring High-Density Active Sites for Chemical Fixation of $\mathrm{CO} 2$ under Ambient Conditions. Chem. Commun. 2014, 50 (40), 5316-5318.

(32) Bueken, B.; Vermoortele, F.; Vanpoucke, D. E.; Reinsch, H.; Tsou, C.-C.; Valvekens, P.; Baerdemaeker, T.; Ameloot, R.; Kirschhock, C. E.; Speybroeck, V.; Mayer, J. M.; De Vos, D. A Flexible Photoactive Titanium Metal-Organic Framework Based on a $\left[\mathrm{Ti}^{\mathrm{IV}}{ }_{3}\left(\mu_{3} \mathrm{O}\right)(\mathrm{O})_{2}(\mathrm{COO})_{6}\right]$ Cluster. Angew. Chem., Int. Ed. 2015, 54 (47), 13912-13917.
(33) Schubert, U. Chemical Modification of Titanium Alkoxides for Sol-Gel Processing. J. Mater. Chem. 2005, 15 (35-36), 3701-3715.

(34) Ahmed, E.; Holmström, S. Siderophores in Environmental Research: Roles and Applications. Microb. Biotechnol. 2014, 7 (3), 196-208.

(35) (a) Dhakshinamoorthy, A.; Asiri, A. M.; García, H. MetalOrganic Framework (MOF) Compounds: Photocatalysts for Redox Reactions and Solar Fuel Production. Angew. Chem., Int. Ed. 2016, 55 (18), 5414-5445. (b) Dhakshinamoorthy, A.; Li, Z.; García, H. Catalysis and photocatalysis by metal organic frameworks. Chem. Soc. Rev. 2018, 47, 8134-8172. (c) Dhakshinamoorthy, A.; Navalón, S.; Corma, A.; García, H. Photocatalytic $\mathrm{CO}_{2}$ reduction by $\mathrm{TiO}_{2}$ and related titanium containing solids. Energy Environ. Sci. 2012, 5, 92179233. (d) Nguyen, H. L. The chemistry of titanium-based metalorganic frameworks. New J. Chem. 2017, 41, 14030-14043.

(36) Horiuchi, Y.; Toyao, T.; Saito, M.; Mochizuki, K.; Iwata, M.; Higashimura, H.; Anpo, M.; Matsuoka, M. Visible-Light-Promoted Photocatalytic Hydrogen Production by Using an Amino-Functionalized Ti(IV) Metal-Organic Framework. J. Phys. Chem. C 2012, 116 (39), 20848-20853.

(37) Toyao, T.; Saito, M.; Horiuchi, Y.; Mochizuki, K.; Iwata, M.; Higashimura, H.; Matsuoka, M. Efficient Hydrogen Production and Photocatalytic Reduction of Nitrobenzene over a Visible-LightResponsive Metal-Organic Framework Photocatalyst. Catal. Sci. Technol. 2013, 3 (8), 2092-2097.

(38) Allendorf, M.; Bauer, C.; Bhakta, R.; Houk, R. Luminescent Metal-Organic Frameworks. Chem. Soc. Rev. 2009, 38 (5), 13301352.

(39) Nasalevich, M.; Becker, R.; Ramos-Fernandez, E.; Castellanos, S.; Veber, S.; Fedin, M.; Kapteijn, F.; Reek, J.; van der Vlugt, J.; Gascón, J. Co@NH 2 -MIL-125(Ti): Cobaloxime-Derived MetalOrganic Framework-Based Composite for Light-Driven $\mathrm{H}_{2}$ Production. Energy Environ. Sci. 2015, 8 (1), 364-375.

(40) Chambers, M. B.; Wang, X.; Ellezam, L.; Ersen, O.; Fontecave, M.; Sanchez, C.; Rozes, L.; Mellot-Draznieks, C. Maximizing the Photocatalytic Activity of Metal-Organic Frameworks with Aminated-Functionalized Linkers: Substoichiometric Effects in MIL-125$\mathrm{NH}_{2}$. J. Am. Chem. Soc. 2017, 139 (24), 8222-8228.

(41) Vos, A.; Hendrickx, K.; Voort, P.; Speybroeck, V.; Lejaeghere, K. Missing Linkers: An Alternative Pathway to UiO-66 Electronic Structure Engineering. Chem. Mater. 2017, 29 (7), 3006-3019.

(42) Nasalevich, M. A.; Hendon, C. H.; Santaclara, J. G.; Svane, K.; van der Linden, B.; Veber, S. L.; Fedin, M. V.; Houtepen, A. J.; van der Veen, M. A.; Kapteijn, F.; Walsh, A.; Gascón, J. Electronic Origins of Photocatalytic Activity in $\mathrm{d}^{0}$ Metal Organic Frameworks. Sci. Rep. 2016, 6 (1), 23676.

(43) Wu, X.-P.; Gagliardi, L.; Truhlar, D. G. Cerium Metal-Organic Framework for Photocatalysis. J. Am. Chem. Soc. 2018, 140 (25), 7904-7912.

(44) Ma, T.; Kapustin, E. A.; Yin, S. X.; Liang, L.; Zhou, Z.; Niu, J.; Li, L.-H.; Wang, Y.; Su, J.; Li, J.; Wang, X.; Wang, W. D.; Wang, W.; Sun, J.; Yaghi, O. M. Single-Crystal x-Ray Diffraction Structures of Covalent Organic Frameworks. Science 2018, 361 (6397), 48-52.

(45) Navarro, J. A. The Dynamic Art of Growing COF Crystals. Science 2018, 361 (6397), 35.

(46) Kresse, G.; Furthmüller, J. Efficiency of Ab-Initio Total Energy Calculations for Metals and Semiconductors Using a Plane-Wave Basis Set. Comput. Mater. Sci. 1996, 6 (1), 15-50.

(47) Kresse, G.; Furthmüller, J. Efficient Iterative Schemes for $\mathrm{Ab}$ Initio Total-Energy Calculations Using a Plane-Wave Basis Set. Phys. Rev. B: Condens. Matter Mater. Phys. 1996, 54 (16), 11169-11186.

(48) Perdew, J. P.; Burke, K.; Ernzerhof, M. Generalized Gradient Approximation Made Simple. Phys. Rev. Lett. 1996, 77 (18), 38653868.

(49) Grimme, S.; Antony, J.; Ehrlich, S.; Krieg, H. A Consistent and Accurate Ab Initio Parametrization of Density Functional Dispersion Correction (DFT-D) for the 94 Elements H-Pu. J. Chem. Phys. 2010, 132 (15), 154104. 
(50) Bučko, T.; Hafner, J.; Lebègue, S.; Ángyán, J. G. Improved Description of the Structure of Molecular and Layered Crystals: Ab Initio DFT Calculations with van Der Waals Corrections. J. Phys. Chem. A 2010, 114 (43), 11814-11824.

(51) Heyd, J.; Scuseria, G. E.; Ernzerhof, M. Hybrid Functionals Based on a Screened Coulomb Potential. J. Chem. Phys. 2003, 118 (18), 8207-8215.

(52) Butler, K. T.; Hendon, C. H.; Walsh, A. Electronic Chemical Potentials of Porous Metal-Organic Frameworks. J. Am. Chem. Soc. 2014, 136 (7), 2703-2706. 